\title{
Calprotectin as a marker of inflammation in cystic fibrosis
}

\author{
B E Golden, P A Clohessy, G Russell, M K Fagerhol
}

\begin{abstract}
Calprotectin is an abundant neutrophil cytosolic protein released during neutrophil activation or death. The use of plasma calprotectin concentration as a marker of pulmonary inflammation was tested in 31 children with cystic fibrosis, none of whom was acutely unwell or pyrexic. Twenty three were receiving antibiotics, 21 had positive sputum cultures, but none of the traditional tests clearly diagnosed ongoing infection. Plasma calprotectin was significantly higher in the cystic fibrosis group than in matched controls. Sixteen children with cystic fibrosis had values above the control range $(320-1570 \mu \mathrm{g} / \mathrm{l})$. Their chest radiograph Northern score, an index of accumulated pulmonary involvement, and their plasma copper, an index of acute phase response, both correlated with plasma calprotectin. Plasma $\gamma$-glutamyltransferase also correlated weakly with plasma calprotectin: thus, hepatic pathology may be a confounding variable. However, the data still suggested that plasma calprotectin is a better index of inflammation than the traditional indices in general use.
\end{abstract}

(Arch Dis Child 1996; 74: 136-139)

Keywords: cystic fibrosis, inflammation, neutrophil protein.

The prognosis in cystic fibrosis is largely dependent on the incidence, severity, and duration of pulmonary infections. ${ }^{1}$ Infections cause cumulative lung damage which increases susceptibility to further infection. The lung damage is largely the result of local inflammation associated with bacterial invasion. The dominant cells in this type of inflammation are neutrophils. Enormous numbers of these are mobilised, then activated and killed at the sites of invasion in the lungs. Thus, early in the course of infection, neutrophil turnover increases rapidly.

To improve the prognosis in cystic fibrosis requires early, effective treatment of each infection in order to minimise lung damage. ${ }^{1}$ At present, however, methods of early detection of infection are poor. The presence of pathogenic organisms in sputum does not necessarily equate with tissue invasion and inflammation. Laboratory indicators of the acute phase response, such as leucocyte and neutrophil counts, erythrocyte sedimentation rate and $C$ reactive protein, have proved too insensitive ${ }^{2}$; clinical indicators are non-specific and unreliable. Chest radiographic evidence of consolidation is too late; scores, such as the Northern score for cystic fibrosis, estimate accumulated lung damage as well as ongoing infection. ${ }^{3}$

At sites of infection, when activated neutrophils accumulate and die, they release large amounts of calprotectin, a protein which comprises up to $60 \%$ of neutrophil cytosolic protein, about $5 \mathrm{pg} / \mathrm{cell}$. It is a non-covalently associated trimer, molecular weight $36.5 \mathrm{kDa}$, previously known as $\mathrm{L} 1$ protein, incorporating one light $\left(\mathrm{Ll}_{1}\right.$ or MRP-8) and two heavy $\left(\mathrm{Ll}_{\mathrm{h}}\right.$ or MRP-14) polypeptide chains, each with two calcium binding domains. ${ }^{4}$ During bacterial infection in otherwise healthy patients, plasma calprotectin increases within eight hours of the onset of fever to 40-130 times its concentration in non-infected individuals. ${ }^{5}$ It appears to reflect neutrophil turnover. ${ }^{4}$ Stockley et al found very high plasma calprotectin in 13 adults with cystic fibrosis. ${ }^{6}$ Such patients are prone to have extensive inflammation resulting from chronic and recurrent pulmonary infection and indeed, their values decreased with antibiotic treatment. ${ }^{6}$

In 1973, Wilson et al described a serum protein, 'cystic fibrosis protein', that appeared to distinguish cystic fibrosis homozygotes and heterozygotes from normal. ${ }^{7}$ Later, van Heyningen et al described an immunologically similar protein, 'cystic fibrosis antigen', in granulocytes from normal as well as cystic fibrosis patients. ${ }^{8}$ This protein was mapped to chromosome 1.9 Subsequently, it was shown that cystic fibrosis antigen was either one ${ }^{9} 10$ or a complex ${ }^{11}$ of the two S-100 calcium binding polypeptides, MRP-8 and MRP-14. Each of these had already been associated with chronic inflammatory illnesses such as rheumatoid arthritis. ${ }^{12}$ Amino acid analysis has indicated that calprotectin is also a member of the S-100 family and a complex of the polypeptides, MRP-8 and MRP-14; it is also chromosome 1 derived. ${ }^{4}$ It appears that cystic fibrosis antigen corresponds to one or both of the polypeptide chains in calprotectin. ${ }^{13}{ }^{14}$ However, the presence of free $\mathrm{Ll}_{1}$ or $\mathrm{L}_{\mathrm{h}}$ has not been demonstrated in biological materials unless the samples have been exposed to dissociating agents.

We have tested the hypothesis that plasma calprotectin concentration is an early and sensitive indicator of inflammation associated with bacterial infection in cystic fibrosis, potentially more useful than any of the present methods of distinguishing those cystic fibrosis patients with and without active bacterial infections.

In the present study, we have related plasma calprotectin concentration in children with
Department of Child Health, University of Aberdeen, Medical School, Foresterhill, Accepted 5 September 1995 
and without cystic fibrosis to clinical and laboratory tests of bacterial infection.

\section{Subjects and methods}

Thirty one children with confirmed cystic fibrosis (cystic fibrosis group), 16 girls (5-14 years) and 15 boys (5-15 years) were studied, as outpatients, on the day of their annual review at the Royal Aberdeen Children's Hospital. A further 17 children without cystic fibrosis (control group), each age ( \pm 3 months) and sex matched to 1-4 cystic fibrosis subjects, were also studied just before minor surgery, mainly insertion or removal of grommets. The children and their parents were fully informed about the study and parents gave their written consent. The study was approved by the joint ethics committee of the Grampian Health Board and Aberdeen Royal Hospitals Trust.

The cystic fibrosis group had an array of clinical and laboratory tests which included a requirement for peripheral venepuncture. This was performed first. An extra $3 \mathrm{ml}$ blood sample was taken. Of this sample, $2 \mathrm{ml}$ was anticoagulated with $40 \mu 10 \cdot 1 \mathrm{M}$ EDTA for the calprotectin assay, $1 \mathrm{ml}$ with 30 units of heparin for trace element assays and microbiological experiments (to be reported later). Both subsamples were centrifuged at $1500 \mathrm{~g}$ for 10 minutes and the top two thirds of plasma was gently aspirated and stored at $-20^{\circ} \mathrm{C}$ before analysis.

Calprotectin was measured, in duplicate, by a non-competitive enzyme linked immunoassay. ${ }^{15}$ Briefly, $50 \mu$ l alkaline phosphatase conjugated anticalprotectin was incubated with $50 \mu \mathrm{l}$ sample or standard (in duplicate, and diluted 1 in 50) in microtitre wells coated with an IgG fraction of a rabbit polyclonal anticalprotectin antibody. After washing and addition of substrate, $p$-nitrophenyl phosphate, the optical densities of the samples and standards were determined at $410 \mathrm{~nm}$ on a Minireader II (Dynatech). There was a linear correlation between optical density and calprotectin concentration up to $15000 \mu \mathrm{g} / \mathrm{l}$; samples giving higher optical densities were further diluted and reassayed. Calculations were performed using the advanced applications programme on Minireader II. Immunopurified calprotectin stock standard $(28 \mathrm{mg} / \mathrm{l})$, the polyclonal antibody, and the alkaline phosphatase conjugated antibody were prepared in Oslo.

Plasma zinc and copper concentrations were measured in EDTA samples diluted 1 in 10 with $1 \%$ nitric acid (Aristar grade) by atomic absorption spectrophotometry (Pye Unicam SP9) at the Rowett Research Institute.

Plasma calprotectin, zinc, and copper were measured in all subjects in both groups, cystic fibrosis and control. In the cystic fibrosis group, total and differential leucocyte count, serum $\mathrm{C}$ reactive protein, and immunoglobulins were measured and liver function tests, sputum culture, and chest radiography were also performed as part of their annual review. In the control group, total and differential leucocyte counts were performed in 13 of the 17 subjects.

\section{Results}

None of the children in either group was pyrexic. None of the control group had clinical signs of infection or other evidence of inflammation: in the 13 tested, total and differential leucocyte counts were normal.

All of the cystic fibrosis children were in their 'usual' state of health; none felt acutely unwell. Nineteen were receiving oral antibiotics; five, inhaled antibiotics; and eight, no antibiotics. Fifteen said they never produced sputum unaided. Sputum culture was positive in 21 of 27 samples obtained, of which 16 grew Staphylococcus aureus; 10, Pseudomonas aeruginosa; two, Haemophilus influenzae; one, Pseudomonas cepacia; three, Candida spp; and one, Aspergillus fumigatus. All of the cystic fibrosis children had abnormal chest radiographs. Out of a maximum possible Northern score $^{3}$ of $20((0-4)$ per lung quadrant $+(0-4))$, their median score was 10 (range 5-16); six had a score of 3 (that is, 'severe' changes) in at least one quadrant. Nevertheless, none of the cystic fibrosis children had a raised leucocyte count (range $3 \cdot 8-13.0 \times 10^{9} / 1$ ), only one child had a neutrophil count over $7 \cdot 0 \times 10^{9} / 1$ (range $1.7-10.3 \times 10^{9} / 1$ ), and only four children had a serum $C$ reactive protein concentration over $1 \mathrm{mg} / \mathrm{l}$ (range $<1-2 \cdot 2 \mathrm{mg} / \mathrm{l}$ ). Two children had slightly raised serum IgG, 17.4 and $18.9 \mathrm{~g} / 1$, and the latter child had raised serum $\operatorname{IgA}, 4 \cdot 6$ $\mathrm{g} / \mathrm{l}$; none had raised serum IgM concentration. One child, with a serum $C$ reactive protein of $2.2 \mathrm{mg} / \mathrm{l}$, had a low plasma zinc, $9 \mu \mathrm{mol} / \mathrm{l}$, and high plasma copper, $27 \mu \mathrm{mol} / \mathrm{l}$; each of these is evidence of possible acute phase response. His sputum grew $S$ aureus. Seven children had raised serum activities of both alanine aminotransferase (51-168 U/1) and $\gamma$-glutamyltransferase (61-259 U/l).

Plasma calprotectin concentration in the control group was 321-1657 $\mu \mathrm{g} / 1$ (median 727 $\mu \mathrm{g} / \mathrm{l}$, mean $708 \mu \mathrm{g} / \mathrm{l} ; 95 \%$ confidence interval 320 to $1570 \mu \mathrm{g} / \mathrm{l})$. In the cystic fibrosis group, it was 417-25850 $\mu \mathrm{g} / \mathrm{l}$ (median $1832 \mu \mathrm{g} / \mathrm{l}$ ). For further analyses, all calprotectin data were $\log _{10}$ transformed to obtain normal distributions. Plasma calprotectin was significantly higher in the cystic fibrosis group than in the control group (paired $t$ test, $\mathrm{p}<0.0001$ ) but there was considerable overlap (fig 1). Sixteen of the 31 cystic fibrosis children had values above the control range. Plasma calprotectin did not change with age in the control group. However, it tended to increase with age $(r=0.32, \mathrm{p}=0.08)$ in the cystic fibrosis group. One patient, under 7 years old, whose sputum grew $H$ influenzae, had the highest plasma calprotectin. When her value was excluded, a significant positive linear association between age and $\log _{10}$ plasma calprotectin existed $(r=0 \cdot 48, \mathrm{p}<0 \cdot 01)$. However, plasma calprotectin did not increase with time since first diagnosis of cystic fibrosis or since first sputum was noted. It was similar in those children receiving and those not receiving antibiotics. There was no association between core temperature, total leucocyte or neutrophil count or plasma zinc concentration and plasma calprotectin either in the cystic fibrosis group alone 
or in both groups combined. There was no relationship between serum immunoglobulin concentration (IgG, IgA, IgM, or IgE) and plasma calprotectin in the cystic fibrosis group. However, fig 2 shows a significant positive linear correlation in cystic fibrosis children between chest radiograph Northern scores and $\log _{10}$ plasma calprotectin $(r=0 \cdot 47, \mathrm{p}<0.01)$. Using age and Northern score as independent variables in a stepwise multiple regression, age lost its effect and Northern score became the only predictor. Figure 3 shows a significant positive linear association, in cystic fibrosis and control children, between $\log _{10}$ plasma calprotectin and plasma copper concentration $(r=0.48, \mathrm{p}<0.001)$; there was no such association with plasma zinc. $\log _{10}$ plasma calprotectin was also weakly associated with serum $\gamma$-glutamyltransferase activity $(r=0.35$, $\mathrm{p}=0.06$ ) but with no other index of liver function.

\section{Discussion}

We hypothesised that plasma calprotectin would be a more useful marker of bacterial infection in cystic fibrosis than any of the presently available markers. The results of this study support the hypothesis but do not confirm it. This is mainly because there is no 'gold standard' of infection in cystic fibrosis. On comparing the clinical and laboratory tests of infection, excluding plasma calprotectin, in the cystic fibrosis children, we concluded that neither one nor a combination of the tests allowed us to designate a child infected or not infected. A possible reason for the relatively large overlap in plasma calprotectin between the cystic fibrosis and control groups was that some controls, who were admitted for grommet insertion, may, themselves, have had subclinical upper respiratory infections; our control range for these children was wider than that reported for healthy adults. ${ }^{16}$ The study has shown that if plasma calprotectin is cystic

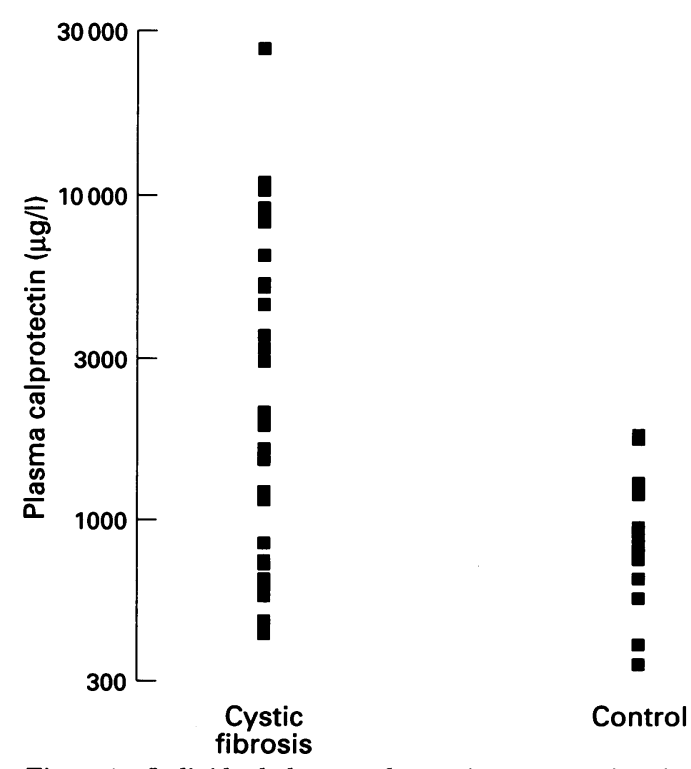

Figure 1 Individual plasma calprotectin concentrations in the 31 children with cystic fibrosis and their matched controls; the group values are different $(p<0.0001)$.

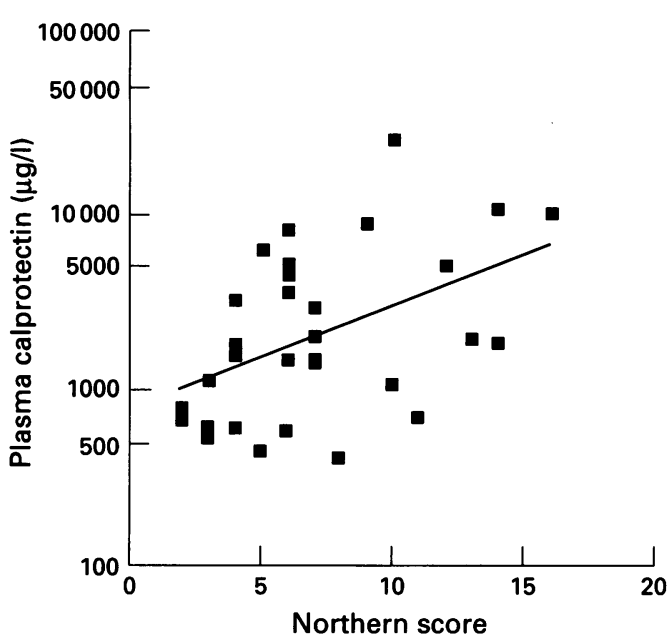

Figure 2 Plasma calprotectin concentrations and chest radiograph Northern score in the cystic fibrosis group only. There is a positive linear correlation between plasma calprotectin $\left(\log _{10}\right)$ and Northern score $(\mathrm{r}=0.47, p<0.01)$.

fibrosis protein or cystic fibrosis antigen, then these are not good markers of cystic fibrosis; almost half the children with cystic fibrosis had values within the control range.

Of the 31 cystic fibrosis children, 23 were receiving antibiotics. None was acutely unwell or pyrexic. Did this clinical observation mean that the right children were being treated with the right antibiotics so that lung damage from infection was being minimised by appropriate treatment? This, we think, is unlikely. Of the 21 (out of 27 tested) cystic fibrosis children with positive sputum cultures, 12 were receiving no antibiotics or antibiotics to which their pathogens were probably insensitive. However, which of these children were infected rather than just colonised is not clear. At least 14 of the 21 children were producing 'mucopurulent' or 'purulent' sputum, which suggests significant inflammation: 10 of these 14 had high plasma calprotectin concentrations. However, unless assessed expertly, this feature, like most other clinical features, is too subjective and insensitive upon which to base treatment.

More objective measures of infection include chest radiographs and markers of an

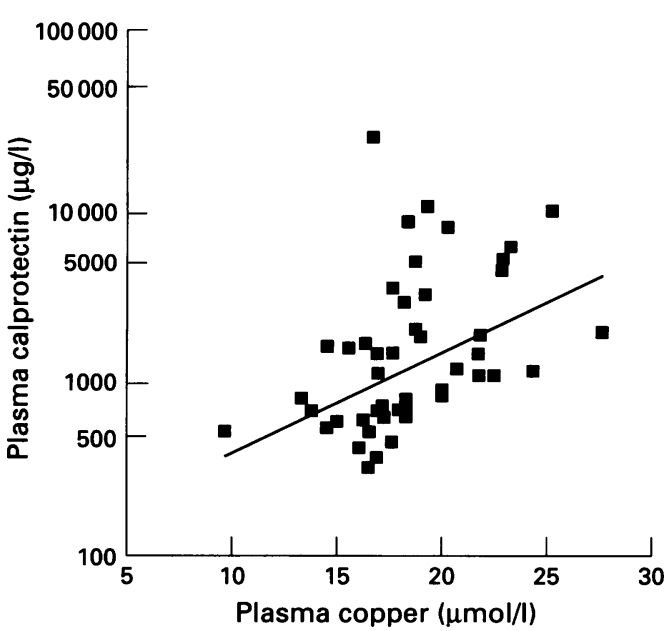

Figure 3 Plasma calprotectin plasma copper concentrations in children with cystic fibrosis and controls. There is a positive linear correlation between plasma calprotectin $\left(\log _{10}\right)$ and plasma copper $(\mathrm{r}=0.48, p<0.001)$. 
acute phase response. Chest radiographs carry a cumulative risk so cannot be repeated frequently; even serial radiographs usually do not allow distinction between acute infection and chronic changes. In this study, they were all abnormal and it was not possible to distinguish those with and without signs of ongoing infection. The Northern score of those with positive sputum culture was slightly but insignificantly higher than those with sterile sputum (mean $7.9 v 5.8$ respectively); its predictive value was too low to be useful. However, their Northern score was associated with their plasma calprotectin, which suggests that the latter is related to the extent of lung involvement.

There was no association among the acute phase response indices measured (leucocyte and neutrophil counts, $C$ reactive protein, plasma zinc and copper) within children, except in one whose serum $C$ reactive protein and plasma copper were raised and plasma zinc was low. His mucopurulent sputum grew $S$ aureus, his Northern score was 13 , but his leucocyte and neutrophil counts were normal. Of the four children with slightly raised $\mathrm{C}$ reactive protein values, two had positive and one had negative sputum culture; the fourth did not produce sputum. The child with the highest Northern score, of 16 , was the only one with raised serum IgG and IgA; his purulent sputum grew $S$ aureus and $P$ aeruginosa but none of the measured acute phase response indices was raised. Thus, none and no combination of the usual objective measures of infection appeared to discriminate between infected and non-infected children in this study. Recently, however, in six adults with cystic fibrosis, Elborn et al demonstrated significant though variable responses in both serum $C$ reactive protein and neutrophil elastase $\alpha_{1}$ antitrypsin complex at the time of first culture of $P$ aeruginosa in sputum. ${ }^{17}$ Thereafter, these acute phase response indices decreased again but the elastase complex remained significantly raised at least until specific antibodies appeared. Like calprotectin, this complex is a neutrophil product whose assay is not yet generally available. Sputum from 10 of our patients grew Pseudomonas spp. They were older than the rest (mean $12.5 v 9.0$ years) and their Northern scores were higher (mean $9 \cdot 4$ $v 6 \cdot 0$ ). However, just one of them had raised serum $C$ reactive protein while six had raised plasma calprotectin compared with 10 of the remaining 21 patients whose sputum did not grow Pseudomonas spp.

Overall, plasma calprotectin was clearly raised in the children with cystic fibrosis compared with their matched controls. It was associated with the Northern score, a measure of lung involvement. It was also associated with their plasma copper concentration. In most if not all situations, this reflects plasma caeruloplasmin, ${ }^{18}$ a copper dependent ferroxidase exported from the liver as part of the acute phase response. Thus, plasma calprotectin is also associated with the acute phase response. Seven children had laboratory evidence of hepatic pathology, presumably inflammation because of bile stagnation or obstruction. There was a weak association between $\gamma$-glutamyltransferase and plasma calprotectin. Thus, it would appear that hepatic pathology is a confounding variable. Treatment of pulmonary and hepatic inflammation may be different. This is a potential drawback to the use of plasma calprotectin as a measure of pulmonary inflammation.

In conclusion, the data suggest that plasma calprotectin is reflecting the extent of ongoing inflammation in patients with cystic fibrosis. They also suggest the need for further studies to test its usefulness in assessing the need for antibiotic treatment.

We thank the Wellcome Trust for supporting this study.

1 Elborn JS, Shale DJ. Lung injury in cystic fibrosis. Thorax 1990; 45: 970-3.

2 Valletta EA, Rigo A, Bonazzi L, Zanolla L, Mastella G. Modification of some markers of inflammation during treatment for acute respiratory exacerbation in cystic fibrosis. Acta Paediatr 1992; 81: 227-30

3 Conway SP, Pond MN, Bowler I, et al. The chest radiograph in cystic fibrosis: a new scoring system compared with the Chrispin-Norman and Brasfield scores. Thorax 1994; 49: 860-2.

4 Fagerhol MK, Andersson KB, Naess-Andresen C-F, Brandtzaeg P, Dale I. Calprotectin (the L1 leukocyte protein). In: Smith VL, Dedman JR, eds. Stimulus response protein). In: Smith VI, Dedman JR, eds. Stimulus response coupling: the role of intracellular calcium-binc

5 Sander J, Fagerhol MK, Bakken JS, Dale I. Plasma levels of the leucocyte L1 protein in febrile conditions: relation to aetiology, number of leucocytes in blood, blood sedimentation reaction and C-reactive protein. Scand $\mathcal{f}$ Clin Lab Invest 1984; 44: 357-62.

6 Stockley RA, Dale I, Hill SL, Fagerhol MK. Relationship of neutrophil cytoplasmic protein (L1) to acute and chronic lung disease. Scand f Clin Lab Invest 1984; 44: 629-34.

7 Wilson GB, Jahn TL, Fonseca JR. Demonstration of serum protein differences in cystic fibrosis by isoelectric focussing in thin-layer polyacrylamide gels. Clin Chim Acta 1973; 49: 79-85.

8 Van Heyningen V, Hayward C, Fletcher J, McAuley C. Tissue localization of a serum protein that tracks the cystic fibrosis gene. Nature 1985; 315: 513-5.

9 Dorin JR, Novak M, Hill RE, Brock DJH, Secher DS, van Heyningen V. A clue to the basic defect in cystic fibrosis Heyningen V. A clue to the basic defect in cystic fibrosis
from cloning the CF antigen gene. Nature 1987; 326: from clon.

10 Bruggen J, Tarcsay L, Cerletti $\mathrm{N}$, et al. The molecular nature of the cystic fibrosis antigen. Nature 1988; 331: 570.

11 Barthe C, Figarella C, Carrere J, Guy-Crotte O. Identification of 'cystic fibrosis protein' as a complex of two calcium-binding proteins present in human cells of myeloid origin. Biochem Biophys Acta 1991; 1096: 175-7.

12 Odink K, Cerletti N, Bruggen J, et al. Two calcium-binding proteins in infiltrate macrophages of rheumatoid arthritis. Nature 1987; 330: 80-2.

13 Andersson KB, Sletten K, Berntzen HB, et al. The leucocyte L1 protein: identity with the cystic fibrosis antigen and the calcium-binding MRP-8 and MRP-14 macrophage components. Scand $\mathcal{f}$ Immunol 1988; 28: 241-5.

14 Brandtzaeg P, Dale I, Gabrielsen T-O. The leucocyte protein L1 (calprotectin): usefulness as an immunohistoprotein L1 (calprotectin): usefulness as an immunohistochemical marker antigen and putathology 1992; 21: 191-6.

15 Roseth AG, Fagerhol MK, Aadland E, Schjonsby H. Assessment of the neutrophil dominating protein calprotectin in feces. Scand $\mathcal{F}$ Gastroenterol 1992; 27: 793-8.

16 Dale I. Plasma levels of the calcium-binding L1 leukocyte protein: standardization of blood collection and evaluation of reference intervals in healthy controls. Scand $\mathfrak{F}$ Clin Lab Invest 1990; 50: 837-41.

17 Elborn JS, Cordon SM, Shale DJ. Host inflammatory responses to first isolation of Pseudomonas aeruginosa from sputum in cystic fibrosis. Pediatr Pulmonol 1993; 15 287-91.

18 Henkin RI, Schulman JD, Schulman CB, Bronzert DA. Changes in total, nondiffusible, and diffusible plasma zinc and copper during infancy. $f$ Pediatr 1973; 82: 831-7. 